\title{
PERCEPÇÃO DE RISCOS E EFEITOS PARA A SAÚDE OCUPACIONAL DE MOTOCICLISTAS PROFISSIONAIS
}

\author{
PERCEPTION OF RISKS AND EFFECTS FOR OCCUPATIONAL \\ HEALTH MOTORCYCLIST WORKERS
}

Ramon Antônio Oliveira', Cristiane Aparecida Silveira²

\section{RESUMO}

Objetivo: Identificar a percepção dos riscos e consequências do trabalho de motociclistas profissionais. Metodologia: Trata-se de um estudo descritivo, quantiqualitativo, utilizando um instrumento semiestruturado. Realizou-se a estatística descritiva para os dados quantitativos e para os qualitativos a análise temática. O estudo foi aprovado pelo Comitê de Ética em pesquisa (CAAE 0026.0.213.00009). Resultado: Constatou-se que, dentre 131 motociclistas entrevistados, sendo $95,4 \%$ do sexo masculino, média 32,5 anos; 54,2\% casados; 45\% com ensino médio completo, 23 (17,6\%) tem outro vínculo empregatício e $12(9,2 \%)$ são celetistas. Quanto aos dados qualitativos, os motociclistas identificaram como riscos: aqueles relacionados à violência, ao trânsito e os ocupacionais propriamente ditos e como consequências do trabalho: os impactos físicos, financeiros e previdenciários. Conclusão: Os motoboys conhecem parte dos riscos aos quais estão expostos, porém nem sempre usam equipamentos de proteção ou adotam práticas prevencionistas. Melhorar suas condições de trabalho e de vida é o grande desafio, tanto para os próprios motoboys como para a sociedade em geral.

Descritores: Acidentes de Trabalho; Saúde do Trabalhador; Acidentes de Trânsito.
${ }^{1}$ Mestre em Enfermagem na Saúde do Adulto pela Universidade de São Paulo (USP), São Paulo, SP, Brasil.

2 Doutora em Enfermagem pela Escola de Enfermagem de Ribeirão Preto da USP(EERPUSP), Ribeirão Preto, SP, Brasil.

\begin{abstract}
Objective: To identify the perception of the risks and consequences of the work of professional bikers. Methodology: Descriptive study using a semi-structured instrument, built by the authors and validated by experts. It was analyzed to descriptive statistics and the qualitative thematic analysis. The study was approved by the Research Ethics Committee (CAAE 0026.0.213.000-09). Results: It was found that among 131 motorcyclists interviewed, $95.4 \%$ of males, mean 32.5 years; $54.2 \%$ married; $45 \%$ with complete secondary education, $23(17.6 \%)$ have another employment relationship and $12(9.2 \%)$ are full-time employees. As for the qualitative data, motorcyclists identified as risks: those related to violence, traffic and occupational hazards themselves and the consequences of work: physical impacts, financing and social security. Conclusion: The motoboys know a part of the risks to which they are exposed, but they do not always wear protective gear or adopt preventive practices. To improve their work conditions is the great challenge, as much for these workers, as for the general society.
\end{abstract}

Descriptors: Accidents at Work; Occupational Health; Traffic Accidents. 


\section{Introdução}

Nos últimos anos é expressivo o crescimento da frota de motocicletas brasileiras, seja devido ao baixo custo para aquisição, financiamento e manutenção da mesma, seja por outros motivos econômicos ou sociais ${ }^{1}$. Além disso, a motocicleta serve também como instrumento de trabalho, para transporte de pessoas (mototáxi) ou de mercadorias (motofrete ou motoentrega).

Grande parte destes motociclistas trabalha por encomendas/deslocamento fazendo com que os mesmos percorram grandes distâncias a um ritmo de trabalho intenso ${ }^{2}$. Neste contexto, representam uma população de grande risco de envolvimento em acidentes, sendo a maioria dos afetados pelos acidentes de trânsito ${ }^{3}$.

Entretanto, o risco de acidente é percebido como intrínseco à ocupação, o que leva alguns trabalhadores a naturalizá-lo. A distinção feita entre acidentes de trabalho "graves" e acidentes ditos "normais" remete à naturalização dos pequenos acidentes e incidentes que ocorrem no dia-a-dia". 0 acidente, para ser considerado "grave", tem que impedir o trabalhador de continuar desempenhando sua atividade. Este processo remete a um mecanismo de defesa psíquica frente às condições agressivas do trabalho, pois os trabalhadores têm consciência dos riscos a que estão expostos, mas, como as medidas de proteção não os evitam totalmente, terminam por dispensá-las para não carregar um símbolo concreto dos perigos presentes no seu trabalho ${ }^{5}$.

Investigar situações de trabalho para a promoção da segurança, para a redução de acidentes, bem como à atenção integral à saúde são estratégias que conferem valor à vida do trabalhador e que devem ser incentivadas e organizadas pelos profissionais de saúde ${ }^{5}$. Além das precárias condições de trabalho, há ainda a informalidade, marca desta categoria profissional ${ }^{6}$.

Diante do exposto, este estudo justifica-se por buscar uma reflexão acerca dos riscos presentes no cotidiano de trabalho dos motociclistas profissionais e como eles são percebidos pelos trabalhadores. Busca-se sensibilizar trabalhadores e gestores que atuam em saúde do trabalhador acerca da construção de políticas e estratégias de promoção da saúde e prevenção de doenças decorrentes destas atividades. Sendo assim, teve-se como objetivo identificar a percepção dos riscos e consequências do trabalho de motociclistas profissionais.

\section{Metodologia}

Trata-se de um estudo descritivo com abordagem quantiqualitativa. Considerando o cálculo da associação de classe havia 300 motociclistas profissionais atuando em 16 estabelecimentos de uma cidade de porte médio do interior de Minas Gerais. Todos os estabelecimentos cadastrados foram visitados e foi utilizada a amostra probabilística aleatória simples, cuja principal característica é a realização de sorteio a partir de uma lista da população, da qual foi escolhida a amostra desejada, sendo que cada elemento tinha a mesma chance de ser sorteado. Para cada sujeito sorteado foram realizadas até três tentativas de entrevista com o mesmo.

Para este estudo, utilizou-se as seguintes variáveis: motoboy é aquele que utiliza a motocicleta no mercado formal ou informal de trabalho, no serviço de tele-entrega de mercadorias e documentos e mototaxista é o que efetua o transporte de passageiros ${ }^{7}$. Seguindo o disposto na Classificação Brasileira de Ocupação, ambos os termos (mototaxista e o motoboy) foram tratados como sinônimos e definidos como motociclista profissional ${ }^{8}$. Não foram avaliadas variáveis de comportamento como o uso de celular ou o desrespeito a leis de transito.

Respeitou-se os critérios de inclusão: motociclistas há mais de um ano, maiores de 18 anos e exclusão: todos aqueles com atuação há menos de um ano e/ou menores de 18 anos.

Para a realização deste estudo, foram seguidas as Diretrizes da Resolução n. 466/12 do Conselho Nacional de Saúde ${ }^{9}$. A pesquisa foi aprovada pelo Comitê de Ética em Pesquisa (CAAE 0026.0.213.000-09) e pelo presidente da associação de motociclistas profissionais da cidade. Todos os participantes do estudo foram esclarecidos sobre a pesquisa e após o consentimento, assinaram o Termo de Consentimento Livre e Esclarecido (TCLE).

Foram sorteados 184 motociclistas profissionais, 10 recusaram-se a participar da pesquisa, 10 não se encaixavam nos critérios de inclusão e 33 não foram encontrados após três tentativas, resultando em 131 trabalhadores entrevistados.

Aentrevista foi gravada utilizando um instrumento tipo questionário semiestruturado. Utilizou-se um Mp4 da Marca Sony. Procedeu-se a transcrição das respostas gravadas, sem correção da linguagem. Posteriormente, foi feita a categorização das respostas das questões norteadoras. As falas foram identificadas pela letra "E" e numeradas consecutivamente. 
Para a discussão dos dados qualitativos foi utilizada a Análise de Discurso segundo $\operatorname{Bardin}^{10}$. A transcrição e organização dos relatos obtidos pelas entrevistas com os sujeitos compuseram a ordenação dos dados e a classificação deu-se a partir da leitura exaustiva destes materiais, identificando-se estruturas de relevância, de onde emergiram as categorias. Já os dados quantitativos foram analisados a partir da estatística descritiva.

\section{Resultados} Tabela 1.

Foram entrevistados 131 motociclistas, cujos resultados da avaliação sociodemográfica estão apresentados na

Tabela 1 - Distribuição dos motociclistas profissionais de um município do interior de Minas Gerais segundo características sócio-demográficas ( $n=131$ ).

\begin{tabular}{|c|c|c|c|}
\hline \multicolumn{2}{|c|}{ Variáveis } & \multicolumn{2}{|c|}{ Total } \\
\hline \multirow{3}{*}{ Sexo } & Masculino & 125 & 95,4 \\
\hline & Feminino & 6 & 4,6 \\
\hline & Total & 131 & 100,0 \\
\hline \multirow{5}{*}{ Faixa Etária } & Até 30 anos & 73 & 55,73 \\
\hline & $31-40$ anos & 39 & 29,7 \\
\hline & 41-50 anos & 12 & 9,2 \\
\hline & Acima 51 & 7 & 5,4 \\
\hline & Total & 131 & 100,0 \\
\hline \multirow{4}{*}{ Estado Civil } & Solteiro & 49 & 37,4 \\
\hline & Casado/Amasiado & 71 & 54,2 \\
\hline & Divorciado & 11 & 8,4 \\
\hline & Total & 131 & 100,0 \\
\hline \multirow{7}{*}{ Escolaridade } & $\begin{array}{l}\text { Ens. Fundamental } \\
\text { Incompleto }\end{array}$ & 16 & 12,2 \\
\hline & $\begin{array}{l}\text { Ens. Fundamental } \\
\text { Completo }\end{array}$ & 29 & 22,1 \\
\hline & Ens. Médio Incompleto & 17 & 13,0 \\
\hline & Ens. Médio Completo & 59 & 45,0 \\
\hline & Ens. Superior Incompleto & 8 & 6,1 \\
\hline & Ens. Superior Completo & 2 & 1,5 \\
\hline & Total & 131 & 100,0 \\
\hline \multirow{4}{*}{$\begin{array}{c}\text { Tempo de habilitação } \\
\text { para conduzir } \\
\text { motocicleta }\end{array}$} & Menos de 1 ano & 6 & 4,6 \\
\hline & Entre 1 e 2 anos & 15 & 11,5 \\
\hline & Entre 3 e 5 anos & 31 & 23,7 \\
\hline & Total & 131 & 100,0 \\
\hline \multirow{3}{*}{$\begin{array}{l}\text { Outro vínculo } \\
\text { profissional }\end{array}$} & Sim & 23 & 17,6 \\
\hline & Não & 108 & 82,4 \\
\hline & Total & 131 & 100,0 \\
\hline
\end{tabular}


Participaram do estudo 131 mototaxistas, sendo 95,4\% do sexo masculino, 55,7\% com idade entre 21 a 30 anos, com média 32,5 anos; $54,2 \%$ casados; $45 \%$ com ensino médio completo.

Analisando o perfil destes trabalhadores, constata-se que a maioria é jovem e tem baixa escolaridade, casada e chefes de família.

Constatou-se ainda que 23 (17,6\%) dos motociclistas tinham outro vínculo empregatício, trabalhando inclusive aos fiais de semana, além da sobrecarga de trabalho e da carga horária estendida, o que aumenta a predisposição aos acidentes.

Somente $12(9,2 \%)$ indivíduos são trabalhadores celetistas e $50(38,2 \%)$ contribuem para a previdência como autônomos (contribuintes individuais). Os outros 62 (47,3\%) não possuíam nenhum tipo de suporte (caso se acidentem) e nenhum tipo de previsão para a aposentadoria.

Ao equiparar as horas trabalhadas e o número de acidentes com motociclistas profissionais, constatou-se que do total de trabalhadores que desempenhavam sua função por mais de 12 horas diárias, $68 \%$ sofreram três ou mais acidentes, o que demonstra relação do excesso de carga de trabalho ao número de Acidentes de Trabalho (AT) vivenciados por estes profissionais.

Quanto aos dados qualitativos, os motociclistas identificaram como riscos: aqueles relacionados à violência, ao trânsito e os ocupacionais propriamente ditos e como consequências do trabalho: os impactos físicos, financeiros e previdenciários, conforme Quadro 1.

Quadro 1- Distribuição dos motociclistas profissionais de um município do interior de Minas Gerais segundo as categorias identificadas quanto aos riscos e consequências do trabalho.

\begin{tabular}{|c|c|c|}
\hline \multirow[t]{2}{*}{ Riscos do trabalho } & \multicolumn{2}{|c|}{ Sujeito } \\
\hline & f & $\%$ \\
\hline Violência & 65 & 49,6 \\
\hline Trânsito & 64 & 48,9 \\
\hline Ocupacionais & 53 & 40,5 \\
\hline Outras & 20 & 15,3 \\
\hline \multicolumn{3}{|c|}{ Consequências do trabalho } \\
\hline Físicos & 85 & 64,9 \\
\hline Financeiros & 60 & 45,8 \\
\hline Previdenciários & 30 & 22,9 \\
\hline
\end{tabular}

Há grande preocupação com o roubo da motocicleta, o instrumento de trabalho e sobrevivência do trabalhador e dependentes. Uma das falas expressa bem esta preocupação:

A gente corre risco [...] de assalto, tem gente que pede moto rouba a moto e deixa a gente [...]. (E7)

[...] passageiros que você não conhece, as vezes o pessoal ta levando drogas e você não sabe que ta levando drogas, ta levando bandido você não sabe que é bandido, ta; "ce" ta se prejudicando por causa disso, "ce" ta trabalhando honesto e ta carregando um "cara" desonesto sem saber. (E1)

Bom primeiro risco é o risco de você virar um cara traficante por que aqui muita gente que, não os motoqueiros, as pessoas que anda com a gente muita gente que não presta, gente da cadeia, gente carregando drogas para tudo que é lado, é gente perigoso de mal humor [...]. (E45)

A questão do trânsito foi relatada pelos profissionais que dizem conhecer bem o ambiente viário e seus fatores de risco. Os sujeitos relatam os diversos fatores que caracterizam como riscos, conforme a fala dos sujeitos:

[...] você pode pegar uma mancha de óleo, cachorro, você pode pegar uma areia, [...] qualquer motoqueiro pode passar numa mancha de óleo cair e machucar. (E39) 
[...] Uma vez, todas as duas vezes com neblina... atrapalhou a visibilidade e eu acabei todas as duas vezes encostando no meio fio [...]. (E35)

Apesar de impactar no risco de acidentes, os fatores "desrespeito, desatenção e negligência" dos demais motoristas nas vias, foram pouco apontados pelos profissionais. Um dos que reconheceu a influência comportamental na gênese dos acidentes, disse:

A eu acho que o principal é a negligência, a imprudência dos motoristas, tanto de carro quantos esses veículos de transportes urbanos, ônibus, circulares, por que eles desrespeitam o limite da moto, por ser menores, jogam em cima. É a falta de habilidade na condução, eles não usam seta, sinalização [...]. (E4)

Outro risco apontado é a longa jornada de trabalho:

[...] a carga horária que a gente tem de 12 horas de trabalho [apesar da Lei No 12.619 de 30 de Abril de 2012 dispor sobre o exercício da profissão de motorista, prevê a cada jornada de 12 horas de trabalho, 36 horas de descanso] que a gente não pode, como motorista, trabalhar 12 horas de trabalho né, então isso traz um problema pra nossa saúde, tanto problema físico como um cansaço muito mental. (E25)

Apontaram ainda o calor/frio:

A gente pega muito vento, sol, isso machuca a pele, na época de chuva, no frio, resfriados, gripes [...]. (E21)

E por fim o risco ergonômico:

[...] tem né, os riscos ergonômico também que, esses problemas aí, muita dor na perna essas coisa assim né, muita dor no corpo, e também tá muito exposto a poluição aí né, o dia todo aí, a cabeça às vezes dói [...]. (E8).

Os riscos a gente podemos ter problema de coluna por andar muito na moto, ficar encurvado na moto, risco de acidente e ter uma fratura. São esses daí mesmo. (E33)

[...] coluna, da problema na coluna, da no pescoço, isso aí é coisa que é eterno nunca mais melhora [...]. (E50)

Quando questionados sobre as consequências do trabalho para os mesmos, eles destacaram: as físicas, financeiras e previdenciárias tais como: lesão corporal, afastamento do trabalho, prejuízos financeiros:

Eu tive uma fratura exposta, foram seis meses de recuperação, e agora depois de um ano e meio eu ainda faço fisioterapia, pra reabilitação do, da perna esquerda, pra recuperar os movimentos (E4).

Eu tive, eu tenho uma dor no pé que eu não tinha antes. Ganhei peso, porque eu fiquei muito tempo parado, fiquei quase um ano andando de muleta. Essas é uma das piores consequências, no começo teve consequências financeiras mas depois foram resolvidos, que eu recebi ajuda do pessoal aí e salário família do INSS (E40).

\section{Discussão}

A predominância de homens nesta categoria é marcante. Em um estudo realizado em Rio Branco com vítimas motociclistas constatou-se que $89,8 \%$ eram do sexo masculino ${ }^{11}$. Em estudo feito em Feira de Santana, Bahia, constatouse que dos acidentes entre mototaxistas no transito $99,3 \%$ eram referentes ao sexo masculino ${ }^{6}$. 
O homem se sente mais competente na direção do que as mulheres e, percebendo menos os riscos enquanto dirige. O homem tende também a ser mais agressivo, fazendo manobras mais arriscadas; as mulheres são mais prudentes, correm menos e sabem esperar para entrar com segurança em uma via ${ }^{12}$.

A maioria nesta profissão é jovem. Segundo um estudo feito na Feira de Santana, Bahia, a média de idade dos mototaxistas entrevistados foi de 37,4 anos evidenciando a alta taxa de adultos jovens efetuando esse trabalho ${ }^{6}$. Em outro estudo, maior percentual referente à idade foi de $49,5 \%$ compreendidas de 20 a 29 anos $^{12}$.

Referente ao estado civil de trabalhadores mototaxistas de um estudo realizado no Rio Grande do Sul constatouse que $33,4 \%$ são casados, dados semelhantes ao deste estudo ${ }^{13}$.

Verificou-se que 52,8\% possuíam ensino médio completo e apenas um tinha ensino superior, sugerindo a baixa escolaridade da categoria ${ }^{6}$. Em outro estudo, a ocorrência de acidentes moto ciclísticos foi associada significativamente com escolaridade ${ }^{14}$.

Em um estudo foi constatado que $82,9 \%$ dos acidentes ocorreram durante o trabalho. Considerando que a maiorias das jornadas laborais destes trabalhadores são superiores a 10 horas (SOARES et al., 2011, compreende-se que 0 cansaço durante 0 expediente e a falta de intervalos intrajornadas podem ser fatores associados à maior ocorrência de acidentes nesse período.

Os motociclistas profissionais consideram sua profissão insegura e arriscada, embora relevante para a manutenção financeira da família ${ }^{13}$. Além disso, más condições de conservação das vias, presença de animais e de substâncias tornam o asfalto escorregadio e aumentam os fatores de risco para estes sujeitos. Outras questões como a existência de vias de largura imprópria, a baixa iluminação e presença de neblina podem contribuir para a ocorrência de acidentes.

De qualquer modo, às más condições de trânsito no país, alia-se a precariedade das condições de trabalho dos motoboys, o que torna o trabalho nessa profissão realmente muito perigoso.

A cidade em estudo possui as quatro estações do ano em um dia só, sendo o inverno muito rigoroso, agravando os riscos à saúde: os condutores ficam expostos ao frio e também ao calor, devido as variações climáticas intensas. Assim sendo, podem surgir doenças como gripe, dor de garganta, resfriado e/ou bronquite. Além disso, os Equipamentos de Proteção Individual (EPI) utilizados por estes trabalhadores no desenvolvimento de suas funções restringem-se ao capacete, que muitas vezes gera mais calor, e as capas de chuva, que úmidas facilitam a exposição às doenças respiratórias.

Os EPIs protegem os trabalhadores contra riscos de acidentes, mas não se refere a outros equipamentos contra as intempéries. Conforme a Lei n $\mathrm{n}^{0}$ 12.009/09, os mototaxistas devem usar colete de segurança com dispositivo refletivo e instalar equipamentos de segurança nas motos, tais como "protetor de motor mata-cachorro, fixado no chassi do veículo, destinado a proteger o motor e a perna do condutor em caso de tombamento [...] e aparador de linha antena corta-pipas"' . É válido ressaltar que, mesmo já sendo obrigatória a utilização destes equipamentos, persiste a negligência por parte dos profissionais e dos órgãos fiscalizadores ${ }^{15}$.

O constante movimento do condutor e um ambiente cujos outros condutores e suas máquinas também se movimentam; o ambiente do condutor está continuamente em mudança, surgindo sempre novas situações de risco durante o seu trabalho, da qual o leva sempre a uma reação, gerando por muitas vezes comportamentos que colocam em risco a integridade física ${ }^{16}$.

A percepção das causas de acidentes de moto são multidimensionais, incluindo as áreas relacionadas com a condução, o meio ambiente e as crenças ${ }^{17}$.

Muitos mototaxistas trabalham doentes ou com mal-estar físico, a fim de cumprir com seus compromissos financeiros, o que agrava o problema. Sabe-se que dificuldades relacionadas ao próprio transporte, carga horária elevada e a precariedade das condições de trabalho são alguns dos fatores que contribuem para o sofrimento e adoecimento tais como cansaço, dores no corpo, calor, sono, medo e estresse ${ }^{13}$.

As consequências em saúde representam um grave problema de saúde pública brasileira, levando o Brasil a ter as maiores taxas de mortalidade por acidentes com veículos automotores ${ }^{12}$. Tanto no país, como no mundo, há um grande impacto financeiro destes acidentes ${ }^{18}$.

Esses custos dos acidentes estão associados a fatores diretos como a internação e a diminuição da renda familiar do trabalhador e indiretos como a interrupção prematura de vidas, a incapacidade física e emocional dos vitimados sobreviventes, a perda por produção e atrasos gerados em função dos acidentes ${ }^{19}$.

Os motociclistas apresentam, em comparação às vítimas dos demais mecanismos de trauma, significativamente maior frequência e gravidade das lesões em extremidades e de custos para o sistema de saúde por serem mais severos ${ }^{20}$. 
Os riscos ocupacionais na atividade laboral destes sujeitos são descritos como uma realidade difícil de conviver devido à frequente ocorrência de acidentes. Em um estudo, $40 \%$ dos motociclistas profissionais referiram pelo menos um acidente nos últimos 12 meses. A reincidência de acidente de trânsito é uma característica presente nessa classe de trabalhadores, visto que $39,6 \%$ dos que relataram acidentes referiram envolvimento em dois ou mais acidentes ${ }^{16}, o$ que explicaria a alta morbimortalidade ocupacional da categoria ${ }^{21}$.

\section{Considerações Finais}

As condições de trabalho e de vida dos motociclistas propiciam diversos riscos à sua saúde, bem como acidentes e adoecimentos. Os motoboys conhecem parte dos riscos aos quais estão expostos, assim como sabem que os acidentes caracterizam-se como uma constante em sua prática profissional.

Desta forma, estes profissionais identificam como riscos a violência à qual estão sujeitos, reconhecendo a profissão como insegura e arriscada por estarem vulneráveis. Já os riscos ocupacionais apontados são a longa jornada de trabalho, as variações climáticas que agravam as condições de saúde e riscos ergonômicos, que podem causar dores em todo corpo ou determinadas regiões ${ }^{22}$.

Constatou-se ainda que os trabalhadores pouco relatam a influencia do desrespeito, desatenção, negligência e imprudência dos motoristas no trânsito.

Para além dos riscos ocupacionais, o trânsito, a imprudência, a falta de fiscalização do trabalho e a informalidade são condições que prejudicam ainda mais a saúde e as condições de vida destes trabalhadores.

São necessárias mudanças na legislação e especialmente na fiscalização trabalhista e previdenciária no sentido de reduzir a informalidade, bem como melhorar a proteção social e sanitária desta classe trabalhadora e, consequentemente, reduzir o impacto na saúde pública. Melhorar suas condições de trabalho e de vida é o grande desafio, tanto para os próprios motoboys como para a sociedade em geral.

\section{Referências}

1. Marín-León L, Belon AP, Barros MB de A, Almeida SD de M, Restitutti MC. Trends in traffic accidents in Campinas, São Paulo State, Brazil: the increasing involvement of motorcyclists. Cad Saúde Pública. 2012;28(1):39-51.

2. Godoi SC, Godoi SC. Suffering and working in the city in forced march. Cad Metrópole. dezembro de 2016;18(36):345-64.

3. Souto CC, Reis FKW, Bertolini RPT, Lins RS de MA, Souza SLB de. Perfil das vítimas de acidentes de transporte terrestre relacionados ao trabalho em unidades de saúde sentinelas de Pernambuco, 2012 - 2014. Epidemiol E Serviços Saúde. junho de 2016;25(2):1-2.

4. Silva EJ da, Lima M da G, Marziale MHP. The concept of risk and its symbolic effects in accidents with sharp instruments. Rev Bras Enferm. outubro de 2012;65(5):809-14.

5. Dejours C. A loucura do trabalho: estudo de psicopatologia do trabalho. Sao Paulo: Cortez; 1992. (5).

6. Amorim CR, Araújo EM de, Araújo TM de, Oliveira NF de. Occupational accidents among mototaxi drivers. Rev Bras Epidemiol. 2012;15(1):25-37.

7. Brasil. Lei n.o 12.009 de 29 de julho de 2009. Regulamenta o exercício das atividades dos profissionais em transporte de passageiros, "mototaxista", em entrega de mercadorias e em serviço comunitário de rua, e "motoboy", com o uso de motocicleta, altera a Lei no 9.503, de 23 de setembro de 1997, para dispor sobre regras de segurança dos serviços de transporte remunerado de mercadorias em motocicletas e motonetas - moto-frete -, estabelece regras gerais para a regulação deste serviço e dá outras providências. [Internet]. 2009. Available at: http://www.planalto.gov.br/ccivil_03/_ ato2007-2010/2009/lei//12009.htm

8. Brasil. Classificação Brasileira de Ocupações (CBO) [Internet]. Ministério do Trabalho e Emprego. 2014 [citado 17 de setembro de 2014]. Available at: http://www.mtecbo.gov.br/cbosite/pages/pesquisas/BuscaPorTituloResultado.jsf

9. Brasil. Resolução CNS n. 466, de 12 de dezembro de 2012. Estabelece as diretrizes e normas brasileiras regulamentadoras de pesquisas envolvendo seres humanos. 2012.

10. Bardin L. Análise de conteúdo. Lisboa: Editora 70; 2005. 
11. Rocha G da S, Schor N. Motorcycle accidents in the municipality of Rio Branco in the State of Acre: characterization and trends. Ciênc Saúde Coletiva. 2013;18(3):721-31.

12. Rodrigues CL, Armond J de E, Gorios C, Souza PC. Acidentes que envolvem motociclistas e ciclistas no município de São Paulo: caracterização e tendências. Rev Bras Ortop. novembro de 2014;49(6):602-6.

13. Silva MB da, Oliveira MB de, Fontana RT. Activity of motorcycle taxi driver: risks and weaknesses self referred. Rev Bras Enferm. 2011;64(6):1048-55.

14. Almeida GCM de, Medeiros F da CD de, Pinto LO, Moura JMB de O, Lima KC. Prevalência e fatores associados a acidentes de trânsito com mototaxistas. Rev Bras Enferm. 2016;69(2):382-8.

15. Vasconcelos MV, Freitas CF, Silveira CA. Caracterização do uso de agrotoxico entre trabalhadores rurais. Saúde St Maria. 2014;40(2):87-96.

16. Soares DFP de P, Mathias TA de F, Silva DW da, Andrade SM de. Motorcycle couriers: characteristics of traffic accidents in southern Brazil. Rev Bras Epidemiol. setembro de 2011;14(3):435-44.

17. Cheng ASK, Ng TCK. Risky driving and the perception of motorcycle accident causes among Chinese motorcyclists in Hong Kong. Traffic Inj Prev. setembro de 2012;13(5):485-92.

18. Sisimwo PK, Mwaniki PK, Bii C. Crash characteristics and injury patterns among commercial motorcycle users attending Kitale level IV district hospital, Kenya. Pan Afr Med J [Internet]. 17 de novembro de 2014 [citado 25 de agosto de 2016];19. Available at: http://www.ncbi.nlm.nih.gov/pmc/articles/PMC4393968/

19. Bacchieri G, Barros AJD. Acidentes de trânsito no Brasil de 1998 a 2010: muitas mudanças e poucos resultados. Rev Saúde Pública. outubro de 2011;45(5):949-63.

20. Parreira JG, Martins RK, Slongo J, Perlingeiro J a. G, Soldá SC, Assef JC, et al. Comparative analysis of the frequency and the severity of diagnosed lesions between pedestrians struck by motor vehicles and other blunt trauma mechanisms victims. Rev Colégio Bras Cir. agosto de 2015;42(4):253-8.

21. Cardoso EM. Morbimortalidade relacionada ao trabalho no estado do Amazonas, Brasil, 2000-2011 [Internet]. 2014 [citado 23 de agosto de 2016]. Available at: http://scielo.iec.pa.gov.br/scielo.php?script=sci_ arttext\&pid=S1679-49742014000100014

22. Miziara ID, Miziara CSMG, Rocha LE. Acidentes de Motocicletas e sua relação com o trabalho: revisão da literatura. Saúde Ética Justiça. 2014;19(2):52-9.

\section{Cristiane Aparecida Silveira}

Endereço para correspondência - Rua: Pe. Francis Cletus Cox, $n^{\circ} 1661$, Bairro: Jardim Country Club, CEP: 37701355 , Poços de Caldas, MG, Brasil.

E-mail: casilve@yahoo.com.br

Lattes: http://lattes.cnpq.br/8840798305145545

Ramon Antônio Oliveira - oliveiraramon@yahoo.com.br

Enviado em 30 de agosto de 2016. Aceito em 17 de novembro de 2016. 